\title{
Spatiotemporal Analysis of Breast Cancer Incidence: A Study in Southern Portugal Between 2005 and 2012
}

\author{
INÊS GOMES ${ }^{1,2}$, ANA MIRANDA $^{3}$ and CARLA NUNES ${ }^{1,4}$ \\ ${ }^{1}$ Epidemiology and Statistics Department, National School of Public Health, \\ NOVA University of Lisbon, Lisbon, Portugal; \\ ${ }^{2}$ Pfizer, Porto Salvo, Portugal; ${ }^{3}$ Southern Portugal Cancer Registry, \\ Portuguese Institute of Oncology of Lisbon, Lisbon, Portugal; \\ ${ }^{4}$ Public Health Research Center, NOVA University of Lisbon, Lisbon, Portugal
}

\begin{abstract}
Aim: To characterize the spatiotemporal patterns of breast cancer $(B C)$ incidence in females in the area with the highest incidence rate (IR) of the country in 2005-2012. Materials and Methods: The BC-IR was studied using mapping techniques, analysis of spatiotemporal clusters and analysis of spatial variations in temporal trends. Results: The overall BC-IR was $119.13 / 10^{5}$ inhabitants. The annual BC-IRs were $17.7,156.9,213.3$ and $232.9 / 10^{5}$ inhabitants for women diagnosed at $<40,40-49,50-64$ and $\geq 65$ years of age. This IR increased overall (by 4.113\%/year) and for the four age groups (by 5.935, 3.833, 4.114 and $2.194 \% /$ year, respectively). In patients with locoregional and metastatic disease, the IRs were 93.6 and $7.4 / 10^{5}$ inhabitants, increasing by 6.976 and $0.303 \% / y e a r$, respectively. Several spatiotemporal clusters and two spatial-variations in temporal trends were detected. The Lisbon region showed high IR clusters for most groups. Conclusion: This study identified critical areas of high IR and increasing trends for female BC-IR, providing evidence of heterogeneities in this area.
\end{abstract}

Breast cancer (BC) is the second most common cancer worldwide and the most frequent malignant disease in women (1-3). This age-associated malignancy (2, 4-9) represented $25 \%$ of female cancer worldwide in $2012(2,3)$ and in Europe corresponded to $27.4 \%$ (10) and 28.9\% (11) of cancer in women in 2004 and 2006, respectively. In 2012, the age-adjusted (world population) BC incidence rate (IR) in the world, Europe (EU) and Southern EU were 43.3, 71.1

Correspondence to: Carla Nunes, Epidemiology and Statistics Department, National School of Public Health, NOVA University of Lisbon., Av. Padre Cruz 1600-560 Lisbon, Portugal, Tel: +351 217512100 , Fax: +351 2175182 754, e-mail: cnunes@ensp.unl.pt

Key Words: Breast neoplasms, incidence, Portugal, space-time clustering, spatio-temporal analysis. and $74.5 / 10^{5}$ inhabitants, respectively (3), being the most common cancer in women in all European countries (12). The age-adjusted European BC-IR (for the EU population) in the same year was $94 / 10^{5}$ inhabitants $(4,12)$ [EU-27 median incidence: $109 / 10^{5}$ inhabitants (12)].

In developed countries, the BC-IR has been rising $(1,2$, $4,6,13-15)$, a growth mostly detected until the year 2000 $(13,16)$ when the use of hormone replacement therapy in older women started to become obsolete $(2,16)$. This change in clinical practice especially affected the IR in older patients $(13,16)$ [ages $50-64$ years $(13,17,18)$ and $65-74$ years $(13$, 17, 18)]. Still, the European BC-IR has been shown to increase with age until age 60-65 years, decreasing then in older women (8). Although some authors have described a stable IR in patients age $<40$ (16) or $<50$ (13) years, an increase of BC-IR has been reported in younger and middleage (15) patients [age 35-49 (17)]. A European study on IR detected a growth (1-3\%/year) of BC among women age $<40$ years in 1995-2006 (19), which might be explained by screening programs and exposure to predisposing factors (19). Additionally, a Swiss registry analysis showed a 1.6$2.7 \%$ growth of BC-IR in women $<40$ years (15), and in France a small increment in this IR also was described for women of this age (18). Conversely, in the UK, the BC-IR increased in 1993-2014 for women $\geq 65$ years but stabilized in patients age 25-49 and 50-64 (6). Notably, when looking at women aged 50-69 years, the BC-IR increased for women in the UK in 1981-2009 (20) and for Italian women in 19851994 (21). This growth could potentially reflect screening actions $(2,15,20)$ as the BC-IR plateaued in subsequent years $(6,20)$. Finally, an Italian study indicated an increase in local BC cases between 1985 and 1994 (21), but a decrease in regional and metastatic cases was detected (21).

An increase in BC cases also was described in Portugal (22-24), with 47,868 and 4,300 new cases being diagnosed in 1995-2009 (25) and in 2002 (26), respectively. In 2008, 2010 and 2012, about a third of new Portuguese female 
neoplasm cases were of BC (30.2, 31.1 and 29.4\%, respectively) (27-29). In 2007 and 2009, the Portuguese female BC-IR was $101.80 / 10^{5}$ inhabitants (standardized IR: $82.40 / 10^{5}$ inhabitants) (30) and $110.12 / 10^{5}$ inhabitants (standardized IR for the EU population: $87.58 / 10^{5}$ inhabitants) (24). In 2010 and 2012, BC was the leading cancer diagnosis in Portuguese women $(12,22,28)$ with a standardized IR (EU) of 93.2/10 5 inhabitants (28) [unadjusted and standardized IR world population: 118.5 and $69.8 / 10^{5}$ inhabitants (28)] and 85.6/10 5 inhabitants (12) [age-adjusted IR $67.6 / 10^{5}$ inhabitants (29)], placing Portugal on the highest quintile of BC-IR according to the World Health Organization (1). A European study also revealed that between 1990 and 2008, the incidence of BC in young Portuguese women ( $<40$ years) grew, reaching an IR of $14.54 / 10^{5}$ inhabitants (23). Additionally, evidence suggests that significantly more Portuguese BC cases are being diagnosed at a local stage, mainly due to screening actions (30).

In the periods 2000-2004 and 2005-2009, 59.4\% and $63.3 \%$ of new Portuguese BC cases among women were diagnosed in the region covered by the South Regional Cancer Registry (ROR-Sul) (25), and in 2008 and 2010, this region registered $51.16 \%$ (27) and $49.41 \%$ (28) of BC incident cases among women in the country. This registry also showed the highest standardized BC-IR of the four active regional registries [2008: 98.3 vs. 86.6, 69.4 and $83.9 / 10^{5}$ inhabitants in North, Centre and Azores (27); 2010: 97.6 vs. $91.7,83.2$ and $96.5 / 10^{5}$ inhabitants, respectively (28)].

The study of the spatial distribution of diseases and its determinants, the analysis of spatiotemporal clusters $(31,32)$ and spatial variations in temporal trends (33) have been used to study geographic patterns of cancer (34) and are fundamental as public health $(31,32)$ statistical tools. Several studies conducted in China (35-37), Japan (38), Canada (39) and the USA $(40,41)$ detected intra-regional and temporal variations in $\mathrm{BC}$ incidence using these methods. This type of cluster analysis allowed the identification of areas with a higher risk of this cancer (36), provided a basis for the study of local risk factors [example: pollution (35)] and analyzed the role of the health services and lifestyles of the different populations in a defined area or city (35). These results can have public health implications, namely when it comes to resource allocation(36), planning of new epidemiological studies (40), risk assessment and health management (37).

$\mathrm{BC}$ is still a pathology with a high variability in terms of incidence evolution in different countries and regions (1, 3, $12,22,27,28)$. Until now, however, only one study on BC incidence clustering has been conducted in Portugal (42). No further evidence was identified regarding the spatialtemporal variations of $\mathrm{BC}$ incidence in this country.
Therefore, we conducted a spatiotemporal analysis of BC incidence between 2005 and 2012 in the south of Portugal, the region with the highest incidence and IR for this cancer, with the main goal of characterizing the spatiotemporal patterns of BC incidence among women in the period 20052012, considering four age groups and according to the stage at diagnosis.

\section{Materials and Methods}

Data and sources. A retrospective and observational study was carried out. The number of new BC cases diagnosed among women in 2005-2012 in the south of Portugal was obtained from the RORSul. This database is registered in the National Commission for Data Protection (No. 1973500003, December 1997). For this specific study, Ethics Committee approval and informed consent were not required because the data were based on an official national surveillance system and had been previously anonymized. Six counties (out of 126) were not included in this study, as they only started reporting cancer cases to ROR-Sul in 2009. The median female population per year and per county was obtained from Statistics Portugal (SP).

Analytical methods. Firstly, a descriptive analysis of the number of incident BC cases/area/year was performed. Patients were divided into four age groups based on the literature: $<40,40-49$, $50-64$ and $\geq 65$ years $(5-7,13-19,21,23)$. The annual IR was defined as the number of new BC cases among women in a certain area in a determined year, divided by the median population (at 30 June) of female inhabitants in that same area and year (20). Two spatial units were used in this study: the area covered by ROR-Sul, and the mainland counties covered by the registry $(n=109)$. The annual and global BC-IR for southern Portuguese women was calculated as an unadjusted rate and was standardized according to the European and World standard population by indirect standardization.

Four different populations were used for the standardizations two for Europe [EU1976 (43) and EU2010 (44)] and two for the world [World (43) and World2000-2015 (45)] to allow external comparisons (43) and reflect an age distribution closer to the current demographic pattern $(44,45)$. Furthermore, the global and yearly IR were determined as unadjusted rates according to the defined four age groups and BC stage at diagnosis (locoregional disease or metastatic disease). The identification of temporal and spatiotemporal clusters plus the detection of spatial variations in temporal trends was conducted using the Software for the Spatial and Space-Time Scan Statistics (SaTScan ${ }^{\mathrm{TM}}$, version 9.4.4; Martin Kulldorff, Boston, MA, USA), applying circular windows with a maximum of $20 \%$ of the studied population. For these analysis, only the 109 counties in the ROR-Sul mainland were considered. The median population density in the period in analysis was calculated for each of the counties and cut-off values of 150 and 300 inhabitants $/ \mathrm{km}^{2}$ were applied for the definition of rural, intermediate and urban areas (46). The significance level was set at 0.05 , and the IR was expressed per $10^{5}$ inhabitants. The data were analyzed using Statistical Package for Social Sciences (SPSS ${ }^{\mathrm{TM}}$, version 22 for Windows; IBM Corp., Armonk, NY, USA), and the results were mapped using the software QGIS ${ }^{\mathrm{TM}}$ (version 2.18s; Free Software Foundation Inc., Boston, MA, USA). 
Gomes et al: Spatiotemporal Analysis of BC in Southern Portugal

Table I. New female breast cancer cases, unadjusted incidence rate (IR) and standardized incidence rate [(SIR) for the European (EU) and World Population], in the Southern Portugal Cancer Registry (ROR-Sul) per 105 inhabitants, in the period 2005-2012.

\begin{tabular}{ccccccc}
\hline Year & Number of new cases & Unadjusted IR & SIR EU1976 (50) & SIR EU2010 (51) & SIR World (50) & SIR World2000-2025 (52) \\
\hline 2005 & 2,412 & 95.42 & 80.607 & 59.806 & 94.105 & 65.219 \\
2006 & 2,505 & 98.47 & 82.620 & 61.257 & 96.594 & 66.901 \\
2007 & 2,693 & 105.12 & 88.566 & 66.088 & 103.013 & 71.730 \\
2008 & 2,987 & 115.75 & 96.291 & 71.740 & 112.481 & 78.156 \\
2009 & 3,070 & 118.17 & 97.817 & 73.082 & 114.133 & 79.766 \\
2010 & 3,088 & 118.16 & 97.553 & 72.891 & 113.427 & 79.322 \\
2011 & 3,207 & 122.37 & 100.791 & 75.100 & 116.670 & 81.656 \\
2012 & 3,240 & 123.76 & 101.208 & 75.594 & 117.056 & 82.012 \\
\hline Total & 23,202 & 119.13 & 93.35 & 69.57 & 108.64 & 75.73 \\
\hline
\end{tabular}

\section{Results}

ROR-Sul. This study included 23,202 women diagnosed with malignant BC (C50) between January 01, 2005 and December 31, 2012 living in the area covered by the RORSul ( $n=120$ counties). Most of the women were Portuguese (96.2\%), and the mean age at diagnosis was 60.84 years [standard deviation (SD) 14.37, range $=15-102$, median $=61.00$ years] . At diagnosis, most patients presented locoregional disease $(n=18,190,78.4 \%)$, and $6.1 \%$ of the patients had metastatic disease $(n=1,413)$. The unadjusted IR for 2005-2012 was $119.126 / 10^{5}$ inhabitants, and this rate increased with age, peaking in the 65- to 69-year-old group. The unadjusted BC-IR showed some fluctuation in 20052012, ranging between 95.42 and $123.76 / 10^{5}$ inhabitants. When standardized for the European and world standard populations, the IR presented lower values than in its unadjusted form, this reduction being more apparent when the new standard populations proposed for 2010 (44) or 2000-2025 (45), respectively, were used (Table I).

When considering the age groups $<40,40-49,50-64$ and $\geq 65$ years, most of the $\mathrm{BC}$ cases in the period under analysis were diagnosed in the older group $(n=9,555,41.2 \%)$. The year that had the highest number of new BC cases was 2012, matching with the peak of new cases in the older group. The $\mathrm{BC}$-IR was lower in the younger age groups $(17.38,155.60$ and $213.65 / 10^{5}$ inhabitants, respectively) than in the group aged $\geq 65$ years $\left(232.33 / 10^{5}\right.$ inhabitants $)$. The IR of all the age groups showed a tendency to increase in the period under analysis. Additionally, the IR for locoregional BC $\left(93.39 / 10^{5}\right.$ inhabitants) showed a growing pattern, whereas that for metastatic BC $\left(7.25 / 10^{5}\right.$ inhabitants $)$ seemed to be stable (Figure 1).

Analysis by county $(n=109)$. In the spatiotemporal analyses, only the 109 counties in the mainland area covered by RORSul were considered, corresponding to a total of 22,154 incident BC cases in the period 2005-2012. The Portuguese counties presenting the highest BC-IR differed over time. In each of the years $1.83 \%$ to $7.34 \%$ of the counties showed no new cases of BC among women; however, no counties presented no cases for the entire period (Table II).

Spatiotemporal analysis $(n=109)$. The IR, temporal and spatiotemporal clusters identified for all the patients, the four age groups and the two groups of stage at diagnosis are further described in Table III and IV and Figure 2.

Spatiotemporal clustering analysis (Figure 2, a-f) identified several areas with high IR with diverse characteristics and dimensions, with Lisbon being the only area always highlighted in all these different settings. Additionally, when considering all patients, two statistically significant spatial variations in temporal trends were detected: Cluster I ( 7 rural counties) - Inland rural Alentejo: 215 cases; inside $v s$. outside trend: $+19.495 \%$ vs. $+3.972 \%$ /year; annual IR: $88.6 / 10^{5}$ inhabitants) and Cluster II (3 rural counties) - inland rural Médio Tejo: 387 cases; inside $v s$. outside trend: $+14.434 \%$ vs. $+3.937 \% /$ year; annual IR: 95.6/10 5 inhabitants. Considering patients with locoregional disease at diagnosis, two spatial variations in temporal trends were identified: Cluster I (3 rural counties) - inland rural Médio Tejo: 213 cases; inside vs. outside trend: $+26.739 \%$ vs. $+6.753 \% /$ year; annual IR: $52.6 / 10^{5}$ inhabitants) and Cluster II ( 2 urban counties) urban seaside Almada-Seixal: 1,374 cases; inside vs. outside trend: $+13.215 \%$ vs. $+6.458 \%$ /year; annual IR: $100.4 / 10^{5}$ inhabitants) (Figure $2 \mathrm{~g}-\mathrm{j}$ ). No spatial variations in temporal trends were identified for the remaining groups analyzed.

\section{Discussion}

To our knowledge, this study was the first spatiotemporal analysis of female BC incidence conducted in Portugal, providing a starting point for future studies conducted in this area. The BC-IR detected in this analysis was $119.13 / 10^{5}$ 


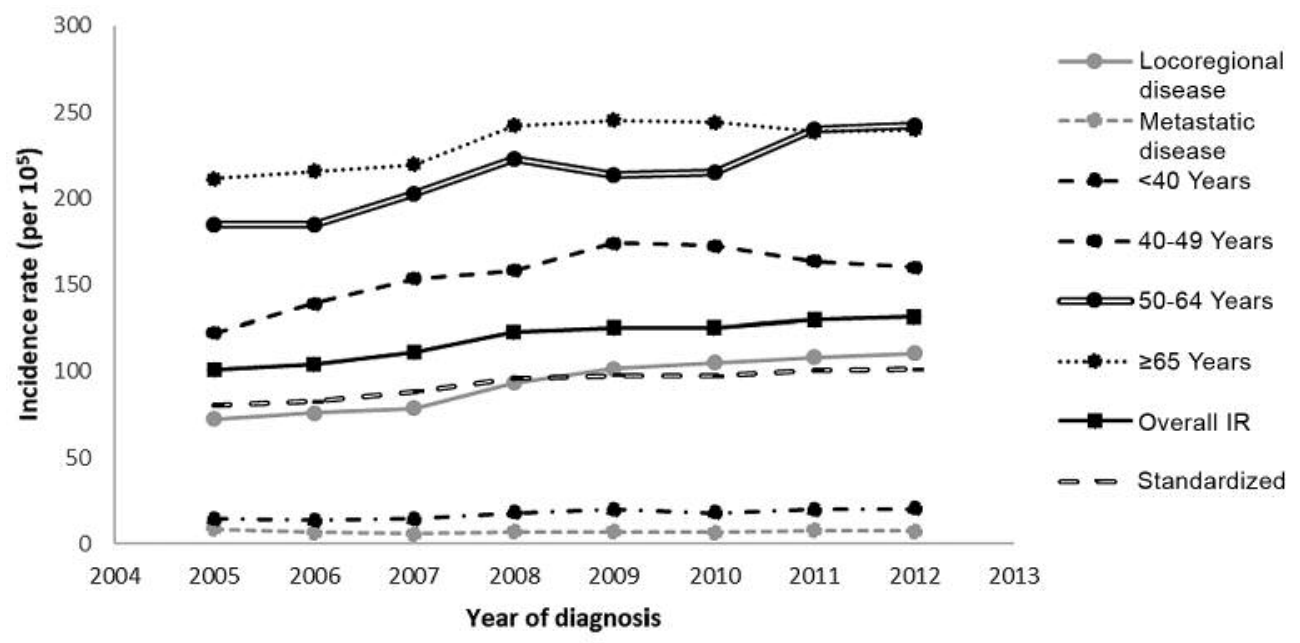

Figure 1. Female breast cancer incidence rate (IR) unadjusted and standardized for the European population(43) per 105 inhabitants. in the Southern Portugal Cancer Registry region between 2005 and 2012: overall and according to the four age groups considered and stage at diagnosis.

Table II. Total and annual number of new breast cancer cases and incidence rate (per $10^{5}$ inhabitants) in the 109 mainland counties covered by the Southern Portugal Cancer Registry in the period of 2005-2012.

\begin{tabular}{|c|c|c|c|c|c|c|}
\hline Year & $\mathrm{N}(\%)$ & $\begin{array}{l}\text { Maximum rate (county, rural/ } \\
\text { intermediate/urban, number of new cases) }\end{array}$ & $\begin{array}{c}\text { Minimum rate } \\
\text { (number of counties; \%) }\end{array}$ & $\begin{array}{l}\text { Mean } \\
\text { rate }\end{array}$ & $\begin{array}{l}\text { Median } \\
\text { rate }\end{array}$ & $\begin{array}{l}\text { Standard } \\
\text { deviation }\end{array}$ \\
\hline 2005 & $2,282(10.3)$ & 204.24 (Almodôvar, rural, $\mathrm{n}=8$ ) & $0(\mathrm{n}=8,7.34 \%)$ & 87.23 & 83.90 & 50.30 \\
\hline 2006 & $2,367(10.7)$ & 252.71 (Mora, rural, $\mathrm{n}=7$ ) & $0(\mathrm{n}=3,2.75 \%)$ & 93.48 & 93.50 & 47.51 \\
\hline 2007 & $2,538(11.5)$ & 212.77 (Mourão, rural, n=3) & $0(\mathrm{n}=6,5.50 \%)$ & 96.35 & 96.76 & 44.52 \\
\hline 2008 & $2,856(12.9)$ & 282.99 (Sousel, rural, $\mathrm{n}=8$ ) & $0(\mathrm{n}=2,1.83 \%)$ & 116.53 & 109.93 & 58.68 \\
\hline 2009 & $2,948(13.4)$ & 365.58 (Lagoa, intermediate, $n=26)$ & $0(n=4,3.67 \%)$ & 122.06 & 119.81 & 58.13 \\
\hline 2010 & $2,964(13.4)$ & 241.98 (Arronches, rural, $n=4$ ) & $0(n=4,3.67 \%)$ & 111.43 & 111.79 & 45.30 \\
\hline 2011 & $3,026(13.7)$ & 371.61 (Sousel, rural, $\mathrm{n}=10$ ) & $0(\mathrm{n}=3,2.75 \%)$ & 124.07 & 122.49 & 62.83 \\
\hline 2012 & $3,092(14.0)$ & 309.60 (Portel, rural, $\mathrm{n}=10$ ) & $0(\mathrm{n}=2,1.83 \%)$ & 120.94 & 118.91 & 53.89 \\
\hline Total & $22,073(100)$ & $158.70($ Lagoa, intermediate, $n=119)$ & $50.69(\mathrm{n}=1,0.9 \%)$ & 109.01 & 105.96 & 54.74 \\
\hline
\end{tabular}

Table III. Number of new breast cancer cases, annual incidence rate (IR), time trends and statistically significant temporal clusters ( $p<0.05)$ in the mainland counties covered by Southern Portugal Cancer Registry ( $n=109)$ between 2005 and 2012: overall, in the four age-groups, and according to the stage at diagnosis.

\begin{tabular}{|c|c|c|c|c|c|c|}
\hline & \multirow[t]{2}{*}{ Number of cases } & \multirow[t]{2}{*}{ Annual IR/10 5} & \multirow[t]{2}{*}{ Time trend (\%/year) } & \multicolumn{3}{|c|}{ Temporal clusters } \\
\hline & & & & Period & Annual IR/10 5 & $\mathrm{RR}$ \\
\hline All patients & 22,154 & 120.6 & +4.113 & $2005-2007$ & 106.0 & $0.82 *$ \\
\hline \multicolumn{7}{|l|}{ Age-groups } \\
\hline$<40$ years & 1,490 & 17.7 & +5.935 & $2005-2007$ & 14.5 & $0.74^{*}$ \\
\hline $40-49$ years & 3,933 & 156.9 & +3.833 & $2005-2006$ & 130.4 & $0.79 *$ \\
\hline $50-64$ years & 7,514 & 213.3 & +4.114 & $2005-2007$ & 189.8 & $0.84 *$ \\
\hline$\geq 65$ years & 9,136 & 232.9 & +2.194 & $2005-2007$ & 213.8 & $0.88^{*}$ \\
\hline \multicolumn{7}{|l|}{ Stage at diagnosis } \\
\hline Locoregional disease & 17,184 & 93.6 & +6.976 & 2009-2012 & 107.0 & $1.34 *$ \\
\hline Metastatic disease & 1,361 & 7.4 & +0.303 & $2005-2005$ & 9.0 & $1.25 * *$ \\
\hline
\end{tabular}

RR, Relative risk. Significant at * $p<0.001 ; * * p=0.027$. 
Table IV. Breast cancer incidence in spatiotemporal clusters on the mainland counties covered by the Southern Portugal Cancer Registry ( $n=109)$ between 2005 and 2012 presenting statistical significance $(p<0.05)$ : overall, in the four age groups considered and according to the stage at diagnosis.

\begin{tabular}{|c|c|c|c|c|c|c|c|}
\hline IR & Group & Period & Cluster $(p<0.05)^{*}$ & $\begin{array}{c}\text { No. of } \\
\text { new cases/ } \\
\text { no. of } \\
\text { counties }\end{array}$ & $\begin{array}{c}\text { Cases } \\
\text { observed/ } \\
\text { expected }\end{array}$ & RR & $\begin{array}{c}\text { Annual } \\
\text { incidence rate/ } \\
10^{5} \\
\text { inhabitants }\end{array}$ \\
\hline \multirow[t]{15}{*}{ High } & \multirow[t]{4}{*}{ All patients } & 2009-2012 & A: Marvão (rural, inland) & $172 / 1$ & 19.71 & 19.86 & $2,378.1$ \\
\hline & & 2009-2012 & B: Lisbon (urban, seaside) & $1,970 / 1$ & 1.39 & 1.42 & 167.2 \\
\hline & & 2009-2012 & C: Greater Lisbon - South (urban, seaside) & $1,511 / 3$ & 1.18 & 1.19 & 142.3 \\
\hline & & 2009-2012 & D: Monchique (urban-rural, inland) & $155 / 1$ & 10.69 & 10.76 & $1,289.5$ \\
\hline & 40-49 Years & 2010 & A: Lisbon (urban, seaside) & $98 / 1$ & 1.85 & 1.87 & 289.9 \\
\hline & $50-64$ Years & $2011-2012$ & A: Lisbon (urban, seaside) & $346 / 1$ & 1.42 & 1.44 & 303.3 \\
\hline & \multirow[t]{3}{*}{$\geq 65$ Years } & 2006-2009 & A: Greater Lisbon - North (urban, seaside) & $707 / 3$ & 1.21 & 1.23 & 281.5 \\
\hline & & $2007-2010$ & B: Lisbon (urban, seaside) & $999 / 1$ & 1.22 & 1.25 & 283.9 \\
\hline & & $2008-2010$ & C: Greater Lisbon - South (urban, seaside) & $415 / 4$ & 1.36 & 1.38 & 317.8 \\
\hline & \multirow{5}{*}{$\begin{array}{c}\text { Locoregional } \\
\text { disease }\end{array}$} & $2007-2007$ & A: Marvão (rural, inland) & $19 / 1$ & 10.62 & 10.63 & 993.5 \\
\hline & & 2009-2012 & B: Lezíria do Tejo (intermediate, inland) & $1,064 / 18$ & 1.21 & 1.22 & 112.9 \\
\hline & & 2009-2012 & C: Lisbon (urban, seaside) & $1,993 / 2$ & 1.37 & 1.42 & 128.6 \\
\hline & & 2009-2012 & D: Greater Lisbon (urban, seaside) & $1,356 / 3$ & 1.37 & 1.40 & 127.7 \\
\hline & & 2009-2012 & E: Alentejo and Algarve (intermediate, inland-seaside) & $1,948 / 37$ & 1.19 & 1.22 & 111.6 \\
\hline & Metastatic disease & $2005-2005$ & A: Lisbon (urban, seaside) & $64 / 2$ & 2.19 & 2.25 & 16.2 \\
\hline \multirow[t]{13}{*}{ Low } & \multirow[t]{6}{*}{ All patients } & 2005-2006 & Médio Tejo (rural, inland) & $35 / 3$ & 0.28 & 0.28 & 123.22 \\
\hline & & $2005-2007$ & Alentejo and Algarve (intermediate) & $1,176 / 55$ & 0.72 & 0.71 & 87.4 \\
\hline & & $2005-2007$ & Greater Lisbon (intermediate) & $887 / 9$ & 0.79 & 0.79 & 95.8 \\
\hline & & $2005-2008$ & Mafra (intermediate, seaside) & $37 / 1$ & 0.22 & 0.22 & 165.96 \\
\hline & & $2005-2008$ & Sintra (urban, seaside) & $762 / 1$ & 0.82 & 0.81 & 98.6 \\
\hline & & $2005-2008$ & Moita (urban, seaside) & $12 / 1$ & 0.072 & 0.072 & 8.7 \\
\hline & \multirow[t]{2}{*}{$<40$ Years } & $2005-2007$ & Centre (rural, inland) & $27 / 36$ & 0.44 & 0.42 & 7.7 \\
\hline & & 2006-2009 & Alentejo (rural) & $39 / 28$ & 0.50 & 0.49 & 8.8 \\
\hline & 40-49 Years & $2005-2006$ & Centre and North Alentejo (rural, inland) & $113 / 60$ & 0.59 & 0.57 & 91.9 \\
\hline & \multirow[t]{2}{*}{ 50-64 Years } & $2005-2006$ & Médio Tejo (rural, inland) & $4 / 3$ & 0.11 & 0.11 & 22.7 \\
\hline & & $2005-2007$ & Alentejo (intermediate) & $407 / 45$ & 0.74 & 0.73 & 158.9 \\
\hline & \multirow[t]{2}{*}{$\geq 65$ Years } & $2005-2008$ & Centre (rural, inland) & $371 / 21$ & 0.71 & 0.70 & 166.5 \\
\hline & & $2005-2007$ & Alentejo and Algarve (intermediate) & $432 / 51$ & 0.65 & 0.63 & 150.8 \\
\hline
\end{tabular}

RR, Relative risk. *Clusters labelled A - E are depicted in Figure 2.

inhabitants, corresponding to a standardized IR of 93.35 or $69.57 / 10^{5}$ inhabitants when considering the EU1976 or EU2010 and 108.64 or $75.73 / 10^{5}$ inhabitants when adjusting for the World or World2000-2025 standard populations. This rate is similar to the European median IR reported in 2012 of $94 / 10^{5}$ inhabitants $(4,12)$. The difference in the standardized IR detected with the use of the EU1976 (43) and the EU2010 (44) populations points to a potential misalignment of the traditionally used standard populations with regards to the aging women in this population. The increase of the IR in the period of analysis (from 95.42 in 2005 to $123.76 / 10^{5}$ inhabitants in 2012 , or $+4.113 \%$ /year for the mainland southern region) is aligned with the growing BC-IR described for developed countries (1, 2, 4, 6, 13-15) and Portuguese women (22-24).

In this study, the BC-IR in the mainland counties of RORSul increased with age $\left(17.7,156.9,213.3\right.$ and $232.9 / 10^{5}$ inhabitants respectively, in the four age groups studied), which is concordant with the literature (2, 4-9). All the mainland counties showed cases of $\mathrm{BC}$, with most of the diagnosis occurring at the locoregional stage of the disease $(77.57 \%)$ and in the elderly population ( $\geq 65$ years: $41.24 \%$ ). All age groups showed an increasing IR trend $(+5.935 \%$, $+3.833 \%,+4.114 \%$ and $+2.194 \%$ /year, respectively), which is concordant with the published international literature $(6$, $15,17-21)$. This increase in IR points to a potential need for healthcare reorganization (25), especially when considering long-term survival in these patients $(4,14,20,25,47)$ and their need to be followed-up by the national healthcare system (25). A statistically significant increase of this IR was further described in the years 2005 and 2009-2012 for patients diagnosed with metastatic and locoregional disease, respectively, when compared with the remaining period, matching previously published data for local $\mathrm{BC}(30)$. 
a

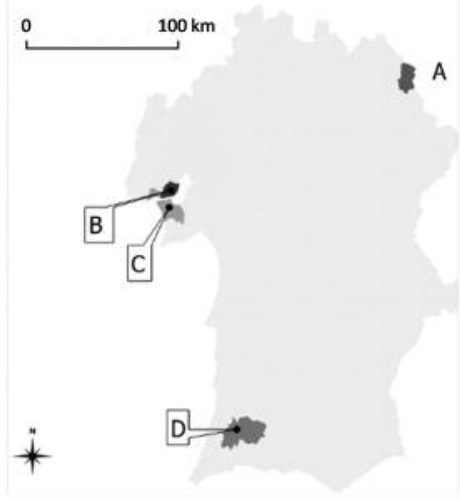

e

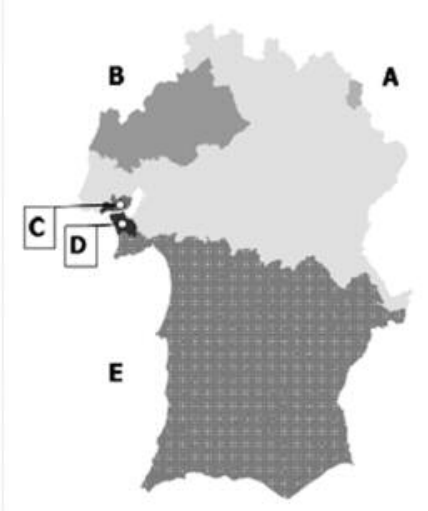

b

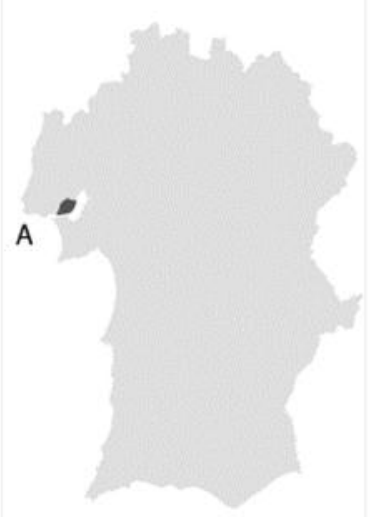

f

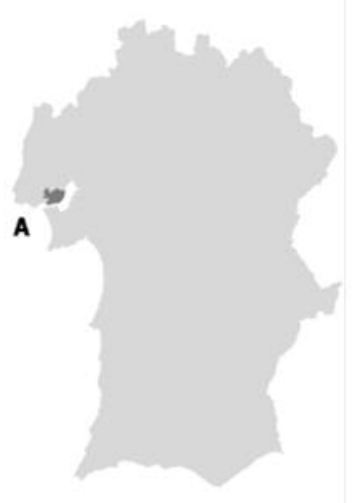

C

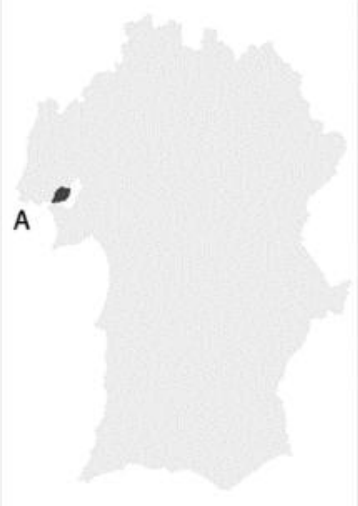

g

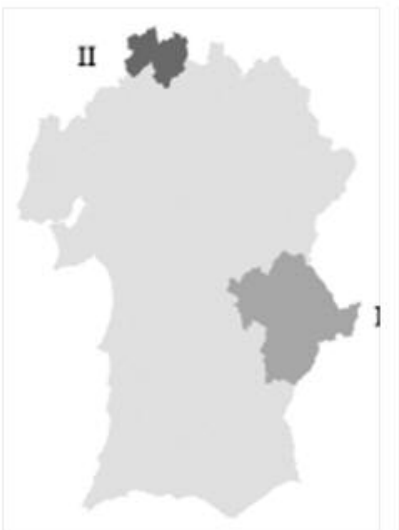

d

A

B

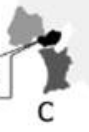

h

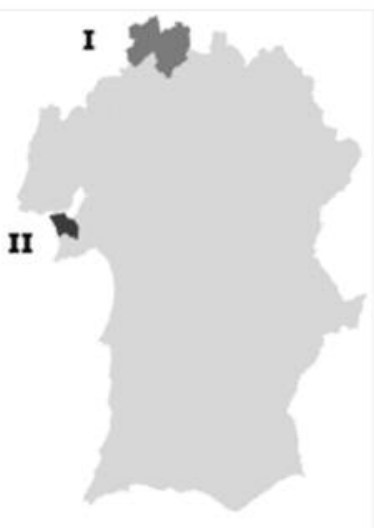

i

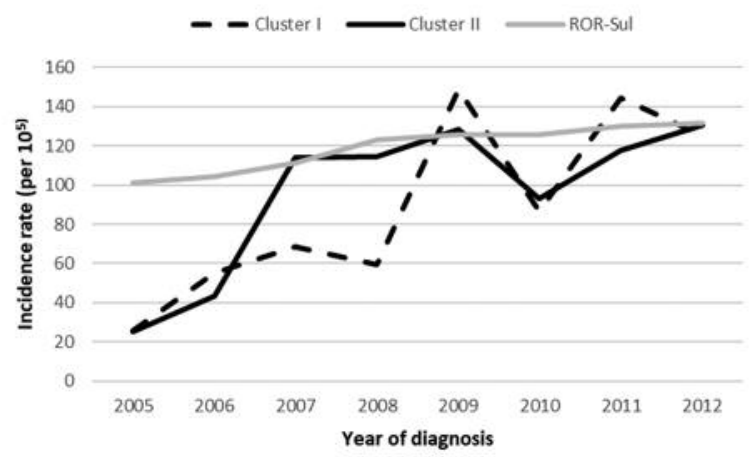

j

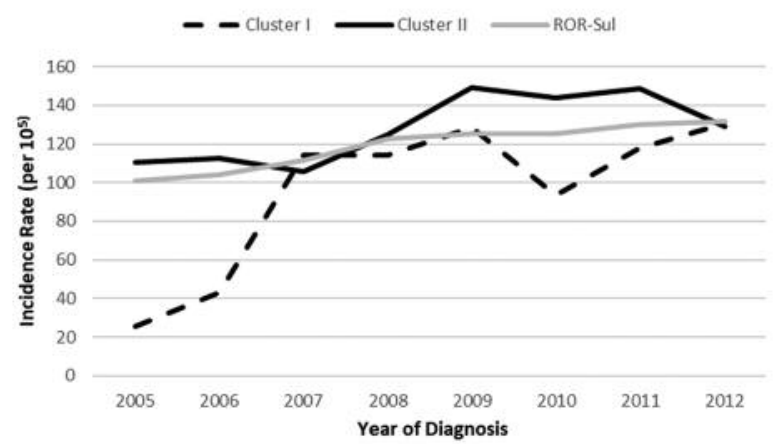

Figure 2. Spatiotemporal clusters of high breast cancer incidence rate $\left[(I R)\right.$ per $\left.10^{5}\right]$ (a-f) and spatial variations in temporal trends ( $\left.g-j\right)$ in the mainland counties covered by the Southern Portugal Cancer Registry ( $n=109)$ between 2005 and 2012: overall (a); at age 40-49 (b), 50-64 (c) and $\geq 65(d)$ years; for those with locoregional disease (e), metastatic disease $(f)$; all patients ( $g$ and $i)$ and locoregional disease ( $h$ and $j$ ). Designations $A-E$ correspond to high IR clusters given in Table IV. Designations I-II correspond to spatial variations in temporal trends clusters described in the text.

Additionally, locoregional cases of $\mathrm{BC}$ have been increasing at a higher rate than metastatic disease (by $6.976 \mathrm{vs}$. $0.303 \% /$ year), a fact than could be a result of screening actions (and early detection of cancer cases) $(2,4-6,12,13$, $17,21,26,30)$ or growing awareness of the population of this health problem $(4,6,12,13,17,18)$. 
Some findings from this analysis should be investigated further, namely the increasing BC-IR trend in young women ( $<40$ years: by $5.935 \% /$ year), as these cases of BC usually are more aggressive $(18,23)$ and are associated with a greater loss of potential years of life (18). Secondly, the Lisbon area was identified as a cluster of high incidence overall, in all the age groups analyzed (except women $<40$ years) and for both metastatic and locoregional disease at diagnosis. High IR clusters identified in this city potentially could be explained by the urbanity of the area $(9,48-50)$. On the other hand, the Alentejo and Algarve intermediate/rural regions showed clusters with lower IR than the average of the studied area for all the age groups considered. These findings might point to the presence of environmental $(4,13,16,49,51)$, genetic (4, $51)$ or lifestyle factors $(4,13,49,51)$ in the capital that predispose patients to the development of this cancer. This excess IR in urban versus rural settings can also be explained by the number of registry hospitals in the urban centers (49) and the fact that patients prefer to be treated in 'renowned' hospitals. This could lead to the use of addresses of family and friends to facilitate access to those facilities (49), inflating the number of cases diagnosed in urban hospitals. The low number of inhabitants could account for the high overall BCIR cluster detected in isolated rural counties (small numbers), whereas the high IR cluster reported for locoregional BC for the intermediate regions matched the previously described trend for BC-IR in Portuguese regions (22).

The spatial variations in temporal trends in the inland rural cluster Médio Tejo showed a dramatic increase in BC-IR (overall and for those with locoregional disease) in 20052012, reaching the values of the regional trend in the last year of the period. This 'exponential' growth in overall BC cases may be due to a sub-detection in the beginning of the period, as suggested by the spatiotemporal cluster Médio Tejo (relative risk=0.28) or higher adherence to screening actions in these years. In addition, the high incidence spatiotemporal cluster in Lezíria do Tejo for patients with locoregional disease (detected at the end of the analyzed period) includes the three counties highlighted by this spatial variation in temporal trend analysis, showing the complementary nature of these methods for the detection of critical areas of $\mathrm{BC}$ incidence. The Alentejo inland rural cluster also presented a variation in the BC-IR dissimilar to that of the region, with two peaks of incidence being described in 2009 and 2011. This phenomenon could be a result of more intense screening actions in these years.

The urban seaside Almada-Seixal cluster showed a trend significantly different from the remaining area in analysis, presenting a higher incidence in all the years studied (except 2007), a fact that might be explained by environmental factors or lifestyle habits in these counties. These counties were also identified as part of the high incidence spatiotemporal clusters for all patients and for those $\geq 65$ years, demonstrating that this area is critical for $\mathrm{BC}$ incidence. Further studies should be carried out to further clarify these findings and to assess if the growing IR trend persisted after the period studied, especially considering that these clusters were detected in the later years of the analysis.

This study presents some limitations, namely the fact that the whole country was not studied and that some cases may have been missed or been recorded in another registry. Additionally, the delay in the public presentation of these data might compromise the relevance of this information for evidence-based public health policies. However, this study provides an innovative, detailed and clear insight into the increase of the $\mathrm{BC}$ burden in this population and on the heterogeneous distribution of this type of cancer.

Southern Portuguese women have shown a growing BCIR; however, the trend for this increase varied according to the age, stage at diagnosis, and area of residence. The reason underlying these different patterns could be related to different distribution $(6,12,17)$, screening methods $(2,4,6$, 12, 17-20) and increase of early diagnosed cases (11). Altogether, these data support the uneven distribution of $\mathrm{BC}$ incidence reported previously in different Portuguese regions $(14,22,25,27,28)$ and the fundamental need for further studies on this topic for a clearer evaluation of potential inequalities in $\mathrm{BC}$ incidence.

\section{Funding and Conflicts of Interests}

This research did not receive any specific grant from funding agencies in the public, commercial, or not-for-profit sectors. There is no conflict of interests to declare.

\section{Acknowledgements}

The Authors thank the ROR-Sul registry for kindly providing the data for this study.

\section{References}

1 International Agency for Research on Cancer - World Health Organization. GLOBOCAN 2012 Estimated Cancer Incidence Mortality and Prevelence Worldwide in 2012. Available from: http://globocan.iarc.fr/ Pages/fact_sheets_cancer.aspx [last accessed May 28, 2016].

2 Torre LA, Bray F, Siegel RL, Ferlay J, Lortet-Tieulent J and Jemal A: Global Cancer Statistics, 2012. CA Cancer J Clin 65: 87-108, 2015.

3 Ferlay J, Soerjomataram I, Dikshit R, Eser S, Mathers C, Rebelo M, Parkin DM, Forman D and Bray F: Cancer incidence and mortality worldwide: Sources, methods and major patterns in GLOBOCAN 2012. Int J Cancer 136: E359-86, 2015.

4 Senkus E, Kyriakides S, Ohno S, Penault-Llorca F, Poortmans P, Rutgers E, Zackrisson F and Cardoso S: Primary breast cancer: ESMO Clinical Practice - Guidelines for diagnosis, treatment and follow-up. Ann Oncol 26: v8-v30, 2015. 
5 Sondik EJ: Breast cancer trends incidence, mortality, and survival. Cancer 74: 995-999, 1994.

6 Cancer Research UK: Breast Cancer incidence (invasive) statistics. Available from: http://www.cancerresearchuk.org/ health-professional/cancer-statistics/statistics-by-cancertype/breast-cancer/incidence-invasive [last accessed July 4, 2017].

7 Keegan TH, Chang ET, John EM, Horn-Ross PL, Wrensch MR, Glaser SL and Clarke CA: Recent changes in breast cancer incidence and risk factor prevalence in San Francisco Bay area and California women: 1988 to 2004. Breast Cancer Res 9: R62, 2007.

8 Curado MP: Breast cancer in the world: Incidence and mortality. Salud Publica Mex 53: 372-384, 2011.

9 Prehn AW and West DW: Evaluating local differences in breast cancer incidence rates: A census-based methodology (United States). Cancer Causes Control 9: 511-517, 1998.

10 Boyle P and Ferlay J: Cancer incidence and mortality in Europe, 2004. Ann Oncol 16: 481-488, 2005.

11 Ferlay J, Autier P, Boniol M, Heanue M, Colombet M and Boyle $\mathrm{P}$ : Estimates of the cancer incidence and mortality in Europe in 2006. Ann Oncol 18: 581-592, 2007.

12 Ferlay J, Steliarova-Foucher E, Lortet-Tieulent J, Rosso S, Coebergh JWW, Comber H, Forman D and Bray F: Cancer incidence and mortality patterns in Europe: Estimates for 40 countries in 2012. Eur J Cancer 49: 1374-1403, 2013.

13 Bray F, McCarron P and Parkin DM: The changing global patterns of female breast cancer incidence and mortality. Breast Cancer Res 6: 229-239, 2004.

14 André M do R, Amaral S, Mayer A and Miranda A: Breast cancer patients survival and associated factors: reported outcomes from the southern cancer registry in Portugal. Acta Med Port 27: 325-330, 2014.

15 Levi F, Te V-C, Maspoli M, Randimbison L, Bulliard J-L and Vecchia C La: Trends in breast cancer incidence among women under the age of forty. Br J Cancer 97: 1013-1014, 2007.

16 Anders CK, Johnson R, Litton J, Phillips M and Bleyer A: Breast cancer before age 40 years. Semin Oncol 36: 237-249, 2009.

17 Botha JL, Bray F, Sankila R and Parkin DM: Breast cancer incidence and mortality trends in 16 European countries. Eur $\mathrm{J}$ Cancer 39: 1718-1729, 2003.

18 Colonna M, Delafosse P, Uhry Z, Poncet F, Arveux P, Molinie F, Cherie-Challine L and Grosclaude P: Is breast cancer incidence increasing among young women? An analysis of the trend in France for the period 1983-2002. The Breast 17: 289292, 2008.

19 Merlo DF, Ceppi M, Filiberti R, Bocchini V, Znaor A, Gamulin M, Primic-Zakelj M, Bruzzi P, Bouchardy C and Fucic A: Breast cancer incidence trends in European women aged 20-39 years at diagnosis. Breast Cancer Res Treat 134: 363-370, 2012.

20 Ellis L, Woods LM, Estève J, Eloranta S, Coleman MP and Rachet B: Cancer incidence, survival and mortality: Explaining the concepts. Int J Cancer 135: 1774-1782, 2014.

21 Barchielli A and Paci E: Trends in breast cancer mortality, incidence, and survival, and mammographic screening in Tuscany, Italy. Cancer Causes Control 12: 249-55, 2001.

22 Direção-Geral da Saúde: Portugal: Doenças Oncológicas em números - 2015: Programa Nacional para as Doenças Oncológicas., 2016. Available from: https://www.dgs.pt/estatisticas- de-saude/estatisticas-de-saude/publicacoes/portugal-doencasoncologicas-em-numeros-2015-pdf.aspx.

23 Leclère B, Molinié F, Trétarre B, Stracci F, Daubisse-Marlia L and Colonna $\mathrm{M}$ : Trends in incidence of breast cancer among women under 40 in seven European countries: A GRELL cooperative study. Cancer Epidemiol 37: 544-549, 2013.

24 Direção-Geral da Saúde: Portugal: Doenças Oncológicas em números - 2014: Programa Nacional para as Doenças Oncológicas, 2014. Available from: https://www.dgs.pt/estatisticas-de-saude/ estatisticas-de-saude/publicacoes/portugal-doencas-oncologicasem-numeros-2014-pdf.aspx.

25 Allemani C, Weir HK, Carreira H, Harewood R, Spika D, Wang X-S, Bannon F, Ahn J V, Johnson CJ, Bonaventure A, MarcosGragera R, Stiller C, Silva GA, Chen W-Q, Ogunbiyi OJ, Rachet B, Soeberg MJ, You H, Matsuda T, Bielska-Lasota M, Storm H, Tucker TC, Coleman MP and Group CW: Global surveillance of cancer survival 1995-2009: analysis of individual data for 25676 887 patients from 279 population-based registries in 67 countries (CONCORD-2). Lancet 385: 977-1010, 2015.

26 Bastos J, Barros H and Lunet N: Evolução da mortalidade por Cancro da Mama em Portugal (1955-2002). Acta Med Port 20: 139-144, 2007.

27 Registo Oncológico Regional do Centro: Registo Oncológico Nacional 2008. (Instituto Português de Oncologia de Coimbra Professor Francisco Gentil EPE (ed.)). Coimbra, 2014. Available from: http://www.roreno.com.pt/images/stories/pdfs/ro_nacional_ 2008.pdf

28 Registo Oncológico Regional do Norte: Registo Oncológico Nacional 2010. (Instituto Português de Oncologia do Porto Professor Francisco Gentil EPE (ed.)). Porto, 2016. Available from: http://www.roreno.com.pt/images/stories/pdfs/ro_nacional_2010.pdf

29 International Agency for Research on Cancer - World Health Organization. GLOBOCAN 2012 Popul Fact Sheets - Port. Available from: http://globocan.iarc.fr/Pages/fact_sheets_ population.aspx [last accessed June 18, 2016].

30 Direcção-Geral da Saúde.: Portugal: Doenças Oncológicas em números - 2013: Programa Nacional para as Doenças Oncológicas., 2013. Available from: https://www.dgs.pt/ estatisticas-de-saude/estatisticas-de-saude/publicacoes/portugaldoencas-oncologicas-em-numeros-2013-pdf.aspx.

31 Nunes C, Briz T, Gomes D and Dias CM: A dimensão espáciotemporal em saúde pública: da descrição clássica à análise de clustering. Rev Port Saúde Pública 26: 5-14, 2008.

32 Lawson AB: Statistical Methods in Spatial Epidemiology. 2nd ed. Chichester, England, John Wiley \& Sons, 2006.

33 Areias C, Briz T and Nunes C: Pulmonary tuberculosis space-time clustering and spatial variation in temporal trends in Portugal, 20002010: an updated analysis. Epidemiol Infect 143: 3211-3219, 2015.

34 Kulldorff $M$ and Nagarwalla N: Spatial disease clusters: detection and inference. Stat Med 14: 799-810, 1995.

35 Fei X, Lou Z, Christakos G, Liu Q, Ren Y and Wu J: A geographic analysis about the spatiotemporal pattern of breast cancer in Hangzhou from 2008 to 2012. PLoS One 11: e0147866, 2016.

36 Zhou H-B, Liu S-Y, Lei L, Chen Z-W, Peng J, Yang Y-Z and Liu $\mathrm{X}$-L: Spatio-temporal analysis of female breast cancer incidence in Shenzhen, 2007-2012. Chin J Cancer 34: 13, 2015.

37 Lou Z, Fei X, Christakos G, Yan J and Wu J: Improving spatiotemporal breast cancer assessment and prediction in Hangzhou City, China. Sci Rep 7: 3188, 2017. 
38 Katayama K, Yokoyama K, Yako-Suketomo H, Okamoto N, Tango $\mathrm{T}$ and Inaba Y: Breast Cancer Clustering in Kanagawa, Japan: A Geographic Analysis. Asian Pac J Cancer Prev 15: 455460, 2014.

39 Luginaah IN, Gorey KM, Oiamo TH, Tang KX, Holowaty EJ, Hamm $\mathrm{C}$ and Wright FC: A geographical analysis of breast cancer clustering in southern Ontario: generating hypotheses on environmental influences. Int J Environ Health Res 22: 232-248, 2012.

40 Vieira VM, Webster TF, Weinberg JM and Aschengrau A: Spatial-temporal analysis of breast cancer in upper Cape Cod, Massachusetts. Int J Health Geogr 7: 46, 2008.

41 Jacquez GM and Greiling DA: Local clustering in breast, lung and colorectal cancer in Long Island, New York. Int J Health Geogr 2: 3, 2003.

42 Paulo J, Santos L and Fernandes G: Breast cancer and environmental factors. In: 16th International Charles Heidelberger Symposium on Cancer Research, 2010.

43 WHO: Glossary - Age-specific rate. Int Agency Res Cancer, 2012. Available from: http://eco.iarc.fr/eucan/Glossary.aspx [last accessed July 3, 2017].

44 Eurostat - European Comission: Revision of the European Standard Population. Luxembourg, 2013.

45 Ahmad OB, Boschi-Pinto C, Lopez AD, Murray CJ, Lozano R and Inoue M: Age standardization of rates: A new WHO standard. World Heal Organ - GPE Discuss Pap 31, 2001.

46 Dijkstra L and Poelman H: Regional working paper 2014: A harmonised definition of cities and rural areas: the new degree of urbanisation (WP01/2014). European Commission, 2014
47 Cancer Research UK: Breast cancer survival statistics. Available from: http://www.cancerresearchuk.org/health-professional/ cancer-statistics/statistics-by-cancer-type/breast-cancer/survival\# heading-Zero [last accessed June 17, 2017].

48 Dey S, Soliman AS, Hablas A, Seifeldein IA, Ismail K, Ramadan M, El-Hamzawy H, Wilson ML, Banerjee M, Boffetta $\mathrm{P}$, Harford J and Merajver SD: Urban-rural differences in breast cancer incidence in Egypt (1999-2006). Breast 19: 417-423, 2010.

49 Hall SA, Kaufman JS, Millikan RC, Ricketts TC, Herman D and Savitz DA: Urbanization and Breast Cancer Incidence in North Carolina, 1995-1999. Ann Epidemiol 15: 796-803, 2005.

50 Krzyżak M, Maślach D, Juczewska M, Lasota W, Rabczenko D, Marcinkowski JT and Szpak A: Differences in breast cancer incidence and stage distribution between urban and rural female population in Podlaskie Voivodship, Poland in years 2001-2002. Ann Agric Env Med 17: 159-162, 2010.

51 Mendes AS, Mateus F, Nogueira J, Branco L, Rodrigues L, Dias SS, Nunes L and Torgal J: Cancro da mama na ilha do Pico (1998-2008): Uma Perspectiva Epidemiológica. Acta Med Port 24: 687-694, 2011

Received December 22, 2017

Revised January 24, 2018

Accepted January 30, 2018 